\title{
BMJ Open Dietary changes and associations with metabolic improvements in adults with type 2 diabetes during a patient-centred dietary intervention: an exploratory analysis
}

\author{
C Y England, ${ }^{1} \mathrm{~J}$ L Thompson, ${ }^{2}$ R Jago, ${ }^{1}$ A R Cooper, ${ }^{1}$ R C Andrews ${ }^{3}$
}

To cite: England CY, Thompson JL, Jago R, et al. Dietary changes and associations with metabolic improvements in adults with type 2 diabetes during a patient-centred dietary intervention: an exploratory analysis. BMJ Open 2014;4: e004953. doi:10.1136/ bmjopen-2014-004953

- Prepublication history for this paper is available online. To view these files please visit the journal online (http://dx.doi.org/10.1136/ bmjopen-2014-004953).

The study was carried out at The University of Bristol, Bristol.

Received 28 January 2014 Revised 13 May 2014 Accepted 20 May 2014

CrossMark

For numbered affiliations see end of article.

Correspondence to

Clare England;

clare.england@bristol.ac.uk

\section{ABSTRACT}

Objectives: Describe dietary intake of participants enrolled in a non-prescriptive dietary intervention and dietary changes at 6 months and explore whether these changes had a role in observed improvements in glycated haemoglobin (HbA1c), weight, lipids and blood pressure.

Design: Secondary analysis of data from the Early ACTivity in Diabetes randomised controlled trial.

Participants: 262 patients with newly diagnosed type 2 diabetes randomised to the dietary intervention.

Outcomes and analysis: Changes in energy intake, macronutrients, fibre and alcohol and in weight, waist circumference, lipids, $\mathrm{HbA1c}$ and blood pressure at baseline and 6 months. Multivariate models were used to examine associations between dietary changes and metabolic variables.

Results: Men reported reducing mean energy intake from $1903 \pm 462 \mathrm{kcal}$ to $1685 \mathrm{kcal} \pm 439 \mathrm{kcal}(\mathrm{p}<0.001)$, increasing carbohydrate intake from $42.4 \pm 6.6 \%$ to 43.8 $\pm 6.6 \%(p=0.002)$ and reducing median alcohol intake from $13(0-27) \mathrm{g}$ to $5(0-18) \mathrm{g}(\mathrm{p}<0.001)$. Women reported reducing mean energy intake from $1582 \pm 379 \mathrm{kcal}$ to 1459 $\pm 326 \mathrm{kcal}(\mathrm{p}<0.001)$ with no change to macronutrient distribution and alcohol. Fibre intake was maintained. In men ( $n=148)$, weak and clinically insignificant associations were found between increased carbohydrates and reduction in HbA1c ( $\beta=-0.003(-0.006,-0.001)$; $\mathrm{p}=0.009$ ), increased fibre and reduction in total cholesterol ( $\beta=-0.023(-0.044,-0.002) ; p=0.033)$, decreased total fat and reduction in low-density lipoprotein (LDL)-cholesterol ( $\beta=0.024$ (0.006, 0.001); $p=0.011)$, and decreased alcohol and reduction in diastolic blood pressure $(\beta=0.276(0.055$, $0.497) ; p=0.015)$. In women ( $n=75)$, associations were found between a decrease in transfats and reductions in waist circumference $(\beta=-0.029(0.006,0.052) ; p=0.015)$, total cholesterol $(\beta=0.399(0.028,0.770) ; p=0.036)$ and LDL cholesterol $(\beta=0.365(0.042,0.668) ; p=0.028)$.

Conclusions: Clinically important metabolic improvements observed in a patient-centred dietary intervention were not explained by changes in macronutrients. However, a non-prescriptive approach may promote a reduction in total energy intake while maintaining fibre consumption.

Trial registration number: The Early ACTID trial number ISRCTN92162869.

\section{Strengths and limitations of this study}

- Describes the dietary intake of people soon after diagnosis of type 2 diabetes mellitus and living in the UK, the dietary changes made during a dietary intervention and explores associations between dietary changes and changes in metabolic outcomes. This intervention was based on the dietary advice that is given in routine clinical practice in the UK.

- The sample was predominantly white but was socioeconomically diverse and $40 \%$ of participants lived in areas of high economic deprivation.

- Only $53 \%$ of the participants provided the food diary data at the end of the trial, and these people showed greater improvements in metabolic outcomes than those who did not return the food diaries. It is probable that they were more motivated than a typical patient group and this limits the generalisability of the findings.

- The use of self-reported dietary measures is a limitation in dietary studies due to the potential for under-reporting food intake.

\section{INTRODUCTION}

Dietary management is recognised as highly important in the treatment of type 2 diabetes mellitus (type $2 \mathrm{DM}$ ). Based on meta-analyses of exercise and diet studies, the American Diabetes Association (ADA) and European Association for the Study of Diabetes (EASD) recommend that lifestyle interventions should be initiated as the first step in treating newonset type 2 DM. $^{1}$ Over the past 3 years, The Look Ahead research group, the Lifestyle Over and Above Drugs in Diabetes (LOADD) and Early ACTivity in Diabetes (Early ACTID) randomised controlled trials (RCTs) have shown that dietary interventions which target weight reduction are beneficial and improve glycaemic control. $^{2-4}$ These trials achieved reductions in glycated haemoglobin (HbA1c) comparable to 
reductions demonstrated in patients starting metformin or a gliptin as monotherapies, ${ }^{5}$ and although the Look Ahead trial showed no reduction in cardiovascular events after 9.6 years, participants in the intervention arm were less likely to be treated with insulin. ${ }^{6}$

It has been reported that changes to the macronutrient composition of the diet may impact on glycaemic control, blood lipids and weight, ${ }^{7}$ but the effects of specific dietary changes on these metabolic outcomes are still unclear and no single 'diet for diabetes' has been identified. ${ }^{8}$ In recognition of this, the 2012 ADA and EASD joint guidelines and 2011 Diabetes UK nutritional guidelines emphasise the importance of an individualised, patient-centred approach to diet rather than a prescriptive approach. ${ }^{1}{ }^{9}$ This approach recognises that different people have individual dietary habits and may find certain dietary changes more straightforward than others. There is evidence that men and women living in the UK have differing dietary patterns. ${ }^{10}$ Men have been reported to drink more alcohol and consume more meat but less fruit and diet soft drinks than women ${ }^{11}$ Few studies have looked at what changes are made to macronutrients in response to non-prescriptive dietary advice, whether men and women make different changes and whether these changes impact on metabolic control.

The Early ACTID trial included a non-prescriptive, patient-centred dietary intervention. The trial aimed to assess whether adding physical activity to a dietary intervention produced greater benefit than diet alone or usual care in individuals newly diagnosed with type 2 DM. ${ }^{4}$ Participants who received the lifestyle interventions had better HbAlc, lower body weight, less insulin resistance and were on less medication than the control group at 6 and 12 months. During the intervention, participants in this cohort reported small changes to higher calorie, low-fibre foods. Examination of the specific changes to foods and food groups reported by participants has been previously published ${ }^{12}$ and this current paper focuses on macronutrients.

The aim of this paper is to describe baseline energy and macronutrient intakes of men and women who were enrolled into the dietary intervention in the Early ACTID study and to examine reported dietary changes made after 6 months.

We conducted exploratory analysis to examine the following hypotheses:

- Men and women with type 2 DM make different dietary changes in response to a dietary intervention.

- The changes to energy intake and macronutrients are associated with beneficial changes to glycaemic control, weight, waist circumference, blood pressure and lipids.

\section{METHODS}

Participants

This paper is an exploratory analysis of data from the Early ACTID RCT. Early ACTID was a diet and physical activity trial involving patients living in the south west of England who were recruited within 5-8 months of a diagnosis of type 2 DM from December 2005 to September 2008. Full trial procedures with the CONSORT diagram and results are described elsewhere. ${ }^{413} 14$ The analysis is limited to participants in the intervention arms who returned valid food diary data.

\section{Overview of the dietary intervention}

Patients in the diet alone and the diet and physical activity groups received the same dietary intervention. For the first 6 months, the intervention aimed to promote dietary change. At randomisation, patients attended a $1 \mathrm{~h}$ appointment with a study dietitian followed by two further visits of $30 \mathrm{~min}$. These visits were supported by six additional visits to a research nurse, where $15 \mathrm{~min}$ were used to discuss dietary matters for both groups, reinforcing dietary goals and $15 \mathrm{~min}$ to discuss either physical activity or other matters pertinent to the patient, depending on the intervention group to which they were allocated. Maintenance was the primary goal of the second 6 months and consisted of two more 30 min dietitian visits and four additional visits to the research nurses.

The dietary intervention was based on the 2003 Diabetes UK healthy eating guidelines ${ }^{15}$ and employed goal-oriented, motivational interviewing ${ }^{16}$ Patients were encouraged to discuss their reasons for change, any ambivalence about change and to set their own dietary goals and identify their own strategies for achieving these goals. Prescriptive daily requirements for energy or macronutrients were not calculated unless requested by the patient and prescriptive meal plans or food lists were not used. Instead, patients received study specific, written dietary information at each visit (available at: http://jcrubristol.org.uk/EA/ACTID\%20patients $\% 20$ Handbook/Forms/AllItems.aspx) and were encouraged to use this to evaluate their own eating habits. The materials included information on maintaining a regular meal pattern and including starchy carbohydrates as a part of each meal, reducing total, saturated and trans fat intake, limiting non-milk extrinsic sugars, aiming for five portions a day of fruit and vegetables and gave guidance on portion control. Specific food choices were discussed and participants were advised on choosing wholegrain and higher fibre foods, reducing fatty and processed meats and high fat dairy products and increasing oily fish and limiting foods such as cakes, biscuits, salty snacks and takeaway meals. The benefit of aiming for a $5-10 \%$ weight loss by reducing overall energy intake was discussed with everyone. Goals were reviewed at each appointment and successes, difficulties and new strategies discussed. Patients were encouraged to self-monitor their weight and diet.

\section{Measurements}

Measures were taken at baseline (prior to randomisation) and repeated 6 and 12 months later. Baseline and 


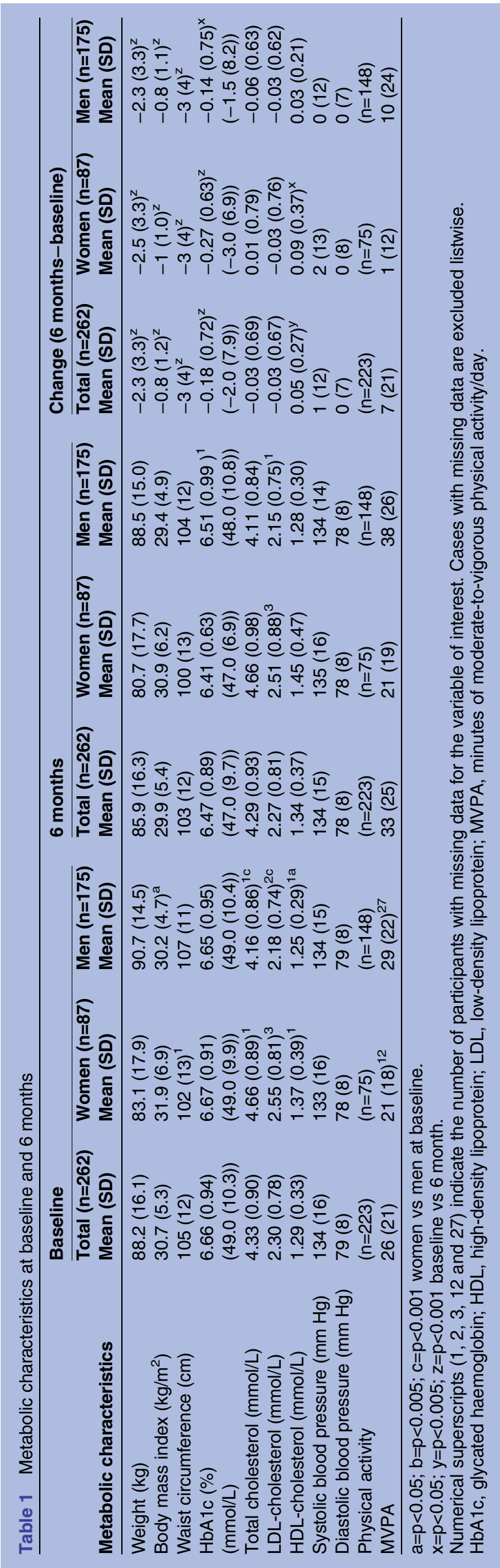

6-month data were used in the current analysis, since outcomes at 6 months were defined as the primary endpoint of the study. Measurements used in this analysis were weight, height (to calculate body mass index (BMI)), waist circumference, blood pressure, HbAlc, fasting lipids and minutes of moderate-to-vigorous physical activity (MVPA) measured using accelerometry and defined as activity expending greater than $3 \mathrm{kcal} / \mathrm{kg} / \mathrm{h}$. As previously described, blood measurements and anthropometric measures were carried out using standardised procedures. ${ }^{13}$ Smoking habits and use of dietary supplements were assessed by a research nurse. The UK Index of Multiple Deprivation (IMD) 2007 was calculated from the home postcode and used as an indicator of socioeconomic position. ${ }^{17}$

\section{Dietary assessment and analysis}

Patients in the intervention arms were asked to complete 4-day food diaries, to include two weekdays and one weekend day, prior to each appointment with a dietitian, recording all foods and drinks consumed during those 4 days. Portion sizes were estimated using household measures and package weights and brands indicated where appropriate. The diaries were discussed during the appointments and used to identify potential areas for change and difficulties in making change, and to enable patients to observe change in their diets over time. Patients were asked to return all the diaries at the final visit for further analysis. Those who did not return the diaries at the visit were reminded by telephone and email to post the outstanding diaries to the research team after the visit.

Baseline and 6-month food diaries were coded by one coder and checked for accuracy and agreement by a second coder, using the dietary coding programme Diet in Data Out (DIDO), developed at the Medical Research Council Human Nutrition Unit in Cambridge, UK. ${ }^{18}$ Diaries were analysed with the nutrient analysis programme Bristol General Analysis of Dietary Experiments (BRIGADE). ${ }^{19}$ The nutrient database is based on McCance and Widdowson's Composition of Foods, 5 th edition, ${ }^{20}$ updated with the supplements to that edition, new data from the 6th edition and manufacturers' data. Additional nutrient data from the INTERMAP nutrient database for the UK were also used..$^{21}$ If no portion size information was given, age-appropriate portion sizes were assigned. ${ }^{22}$ The mean daily consumption of each nutrient was calculated for each participant.

\section{Statistical analysis}

As the dietary intervention was designed to be identical for both intervention groups and there were no difference in outcomes between the diet and diet and physical activity groups, the data were analysed as a cohort. Patients in the usual care group were excluded from the analysis since they did not receive the dietary intervention and were not asked to complete a diary at 6 months. Descriptive statistics were used for patient 
characteristics and for intakes of macronutrients at baseline and at 6 months. Variables were checked for normal distribution; non-normal variables were log transformed prior to analysis. For ease of interpretation, arithmetic means and back transformed variables are presented. Independent $t$ tests were used to explore differences in continuous variables between men and women at baseline and between those who did and did not return food diaries, and $\chi^{2}$ tests were used to explore differences in dichotomous variables. Paired sample $t$ tests were used to describe differences in energy and macronutrient intake between baseline and 6 months. McNemar tests were used to explore differences in numbers of people meeting recommendations at baseline and at 6 months. As alcohol variables could not be transformed, the Mann Whitney $\mathrm{U}$ and paired sample Wilcoxon signed rank test were used to describe differences. Cases with missing data were excluded listwise. Data were assumed to be randomly missing and table 1 includes numerical superscripts to indicate the number of participants with missing data for the variable of interest.

Multivariate regression models were used to conduct exploratory analysis to investigate associations between changes in energy and macronutrient intake and the metabolic variables at 6 months in those who provided valid physical activity data. Changes in energy intake were explored using a standard multivariate model. Each macronutrient was explored independently using a multivariate nutrient density model to adjust for change in energy intake. Change in percentage energy from each macronutrient was calculated and entered into the model with change in total energy included as a covariate. Change in fibre intake was explored using a standard multivariate model and entered as an absolute intake (in Grams) with change to total energy intake as a covariate. ${ }^{23}$ Models were adjusted for age, BMI, time since diagnosis, minutes of MVPA and dichotomous yes/ no variables for smoking status, relevant lipid lowering, blood pressure and diabetes medication and dietary supplement use at 6 months.

Owing to the number of different analyses that were conducted, the results are interpreted in terms of strength of evidence of associations. ${ }^{24}$ This is an exploratory analysis and as such has not been adjusted for multiple comparisons; ${ }^{25}{ }^{26}$ consequently, $\mathrm{p}$ values of $<0.05$ are interpreted as some evidence of association, $\mathrm{p}<0.01$ as increasing evidence and $\mathrm{p}<0.001$ as strong evidence.

\section{RESULTS}

\section{Study participants}

A total of 593 patients were recruited into the Early ACTID study, with 494 being assigned to one of the intervention groups. In total, $396(80 \%)$ patients were recorded as completing food diaries both at baseline and at 6 months, but only $262(53 \%)$ patients returned them. Metabolic and dietary outcomes at baseline and at 6 months are presented for these 262 patients. At
6 months, 491 (99\%) patients assigned to one of the intervention arms remained in the study, with 434 $(88 \%)$ attending all scheduled visits up to that point and a further $37(8 \%)$ attending all except one.

Mean age was 62.4 (9) years, $97 \%$ of patients were white, $83 \%$ were married or with a long-term partner and $41 \%$ were in the lowest IMD quartile. At baseline, $104(40 \%)$ participants were on oral hypoglycaemic medication, $170(65 \%)$ on lipid lowering medication and $174(66 \%)$ on blood pressure medication. Only $6 \%$ of patients were current smokers at baseline. Men and women had similar characteristics, although there was some evidence that men were more likely to be on lipid lowering medication than women $(69 \%$ vs $56 \%$, $\mathrm{p}=0.041)$. At 6 months, $105(40 \%)$ participants were on oral hypoglycaemic medication, although $12(5 \%)$ participants had increased the dose and 4 (2\%) had decreased it; $177(68 \%)$ were on lipid lowering medication and $175(67 \%)$ were on blood pressure medication.

Compared with patients who did not return food diaries, those who did were older (62 vs 57 years, $\mathrm{p}<0.001)$, with a lower mean weight $(88.2 \mathrm{vs} 93.3 \mathrm{~kg}$, $\mathrm{p}=0.001$ ), lower mean BMI (30.7 vs $32.5, \mathrm{p}=0.001$ ) and lower mean waist circumference $(105$ vs $108 \mathrm{~cm}$, $\mathrm{p}=0.025)$, but there was no difference in glycaemic control, lipids and blood pressure.

\section{Metabolic outcomes}

Table 1 shows the metabolic outcomes at baseline and at 6 months for those who returned food diaries. There was no difference in glycaemic control or blood pressure between men and women, but women had higher total $(\mathrm{p}<0001)$ low-density lipoprotein $(\mathrm{LDL} ; \mathrm{p}<0.001)$ and high-density lipoprotein (HDL; $\mathrm{p}=0.015$ ) cholesterol levels.

Weight, waist circumference and BMI improved at 6 months for men and women $(\mathrm{p}<0.001)$. Men and women improved their HbAlc (men: $p=0.006$; women: $\mathrm{p}<0.001)$. Men improved their fasting blood glucose $(p=0.006)$ and there is some evidence that women increased their HDL cholesterol $(p=0.033)$.

At 6 months, those who returned food diaries had lost more weight (2.4 vs $1.3 \mathrm{~kg}, \mathrm{p}=0.001$ ), reduced waist circumference more (2.7 vs $1.3 \mathrm{~cm}, \mathrm{p}=0.022)$ and reduced HbAlc $(0.18 \%$ ( $2 \mathrm{mmol} / \mathrm{L})$ vs $0 \%(0 \mathrm{mmol} / \mathrm{L}), \mathrm{p}=0.02)$.

\section{Nutrient analysis}

Table 2 shows the mean reported energy and nutrient intakes at baseline and at 6 months and their mean reported changes.

At baseline, participants reported generally good dietary habits. $61 \%$ of women and $59 \%$ of men reported the recommended total fat intake (less than $35 \%$ of energy from total fat) and $55 \%$ of women and $66 \%$ of men reported a low-to-moderate carbohydrate intake ( $<45 \%$ of energy). Men were more likely to drink alcohol and more likely to drink to excess than women, with $49 \%$ of women and $28 \%$ of men recording no alcohol during 
Table 2 Nutrient intake at baseline and at 6 months

\begin{tabular}{|c|c|c|c|c|c|c|c|c|c|}
\hline \multirow[b]{2}{*}{$\begin{array}{l}\text { Mean daily intake } \\
\text { nutrients }\end{array}$} & \multicolumn{3}{|l|}{ Baseline } & \multicolumn{3}{|l|}{6 months } & \multicolumn{3}{|c|}{ Change (6 months-baseline) } \\
\hline & $\begin{array}{l}\text { Total } \\
(n=262) \\
\text { Mean (SD) }\end{array}$ & $\begin{array}{l}\text { Women } \\
(n=87) \\
\text { Mean (SD) }\end{array}$ & $\begin{array}{l}\text { Men }(n=175) \\
\text { Mean (SD) }\end{array}$ & $\begin{array}{l}\text { Total } \\
(n=262) \\
\text { Mean (SD) }\end{array}$ & $\begin{array}{l}\text { Women } \\
(n=87) \\
\text { Mean (SD) }\end{array}$ & $\begin{array}{l}\text { Men }(n=175) \\
\text { Mean (SD) }\end{array}$ & $\begin{array}{l}\text { Total } \\
(n=262) \\
\text { Mean (SD) }\end{array}$ & $\begin{array}{l}\text { Women } \\
(\mathrm{n}=87) \\
\text { Mean (SD) }\end{array}$ & $\begin{array}{l}\text { Men }(n=175) \\
\text { Mean (SD) }\end{array}$ \\
\hline Energy (kcal) & $1796(461)$ & $1582(379)$ & $1903(462)^{c}$ & $1610(418)$ & $1459(326)$ & $1685(439)^{\mathrm{c}}$ & $-187(315)^{z}$ & $-123(270)^{z}$ & $-218(332)^{a z}$ \\
\hline Protein (g) & 80 (19) & 73 (16) & $83(20)^{c}$ & 74 (19) & $68(13)$ & $77(20)^{c}$ & $-6(17)^{z}$ & $-5(15)^{y}$ & $-6(19)^{z}$ \\
\hline Total carbohydrates $(\mathrm{g})$ & $202(55)$ & $186(48)$ & $211(57)^{b}$ & $186(53)$ & $170(39)$ & $194(58)^{b}$ & $-17(41)^{z}$ & $-15(33)^{z}$ & $-17(45)^{z}$ \\
\hline Total sugar $(\mathrm{g})$ & 81 (32) & 77 (28) & $83(34)$ & $75(31)$ & $71(23)$ & 77 (34) & $-6(26)^{z}$ & $-6(21)^{x}$ & $-6(28)^{y}$ \\
\hline Starch $(g)$ & $119(36)$ & $105(30)$ & $126(37)^{c}$ & $109(31)$ & $97(26)$ & $115(32)^{c}$ & $-10(28)^{z}$ & $-9(24)^{y}$ & $-11(30)^{z}$ \\
\hline $\begin{array}{l}\text { Non-starch } \\
\text { polysaccharide (g) }\end{array}$ & $17(5)$ & $16(5)$ & $17(5)$ & $16(5)$ & $15(4)$ & $17(5)^{a}$ & $-1(5)$ & $-1(4)$ & $0(5)$ \\
\hline Total fat $(\mathrm{g})$ & $69(22)$ & $61(20)$ & $73(220)^{c}$ & $61(20)$ & $56(19)$ & $64(20)^{b}$ & $-8(18)^{z}$ & $-5(17)^{x}$ & $-9(18)^{z}$ \\
\hline Saturated fat $(g)$ & $23(9)$ & $21(8)$ & $24(9)^{b}$ & $20(9)$ & $19(9)$ & $21(9)$ & $-3(8)^{\mathrm{z}}$ & $-2(7)^{x}$ & $-3(8)^{z}$ \\
\hline Trans fat $(\mathrm{g})$ & $2.3(1.1)$ & $2.0(1)$ & $2.4(1.1)^{b}$ & $2.1(1.1)$ & $1.9(1.1)$ & $2.2(1.1)^{a}$ & $-0.2(1.1)^{y}$ & $-0.1(1.1)$ & $-0.3(1.2)^{y}$ \\
\hline Monounsaturated fat (g) & $24(8)$ & $21(8)$ & $26(8)^{c}$ & $22(8)$ & $20(7)$ & $23(8)^{b}$ & $-2(7)^{z}$ & $-1(8)^{x}$ & $-3(7)^{z}$ \\
\hline Polyunsaturated fat $(\mathrm{g})$ & $13(6)$ & $12(6)$ & $14(6)^{a}$ & $12(4)$ & $11(4)$ & $13(5)^{a}$ & $-1(5)^{z}$ & $-1(6)$ & $-1(5)^{y}$ \\
\hline Alcohol, median (IQR) (g) & $7(0-23)$ & $1(0-12)$ & $13(0-27)^{\mathrm{a}}$ & $4(0-16)$ & $0(0-11)$ & $5(0-18)^{b}$ & $0(-3-1)^{z}$ & $0(-3-4)$ & $-3(-14-0)^{c z}$ \\
\hline$\%$ Energy from protein & $18.3(3.6)$ & $19.0(3.7)$ & $18.0(3.5)^{\mathrm{a}}$ & $18.8(3.5)$ & $19.0(3.3)$ & $18.7(3.6)$ & $0.5(3.7)^{z}$ & $0.0(3.6)$ & $0.7(3.8)^{y}$ \\
\hline $\begin{array}{l}\% \text { Energy from total } \\
\text { carbohydrates }\end{array}$ & $43.2(6.6)$ & $44.8(6.4)$ & $42.4(6.6)^{a}$ & $44.1(6.5)$ & $44.7(6.2)$ & $43.8(6.6)$ & $0.9(6.0)^{z}$ & $-0.1(6.2)$ & $1.4(5.9)^{y}$ \\
\hline$\%$ Energy from total fat & $33.5(5.6)$ & $33.4(5.8)$ & $33.6(5.5)$ & $33.3(5.8)$ & $33.3(6.4)$ & $33.3(5.4)$ & $-0.2(5.9)$ & $-0.1(6.3)$ & $-0.3(5.7)$ \\
\hline $\begin{array}{l}\% \text { Energy from } \\
\text { saturated fat }\end{array}$ & $11.2(3.1)$ & $11.4(3.4)$ & $11.2(3.1)$ & $11.0(3.4)$ & $11.1(3.6)$ & $10.9(3.2)$ & $-0.3(3.3)$ & $-0.3(3.1)$ & $-0.3(3.5)$ \\
\hline$\%$ Energy from trans fat & $1.1(0.4)$ & $1.1(0.43)$ & $1.1(0.5)$ & $1.1(0.5)$ & $1.1(0.4)$ & $1.1(0.5)$ & $0.0(0.5)$ & $0.0(0.5)$ & $0.0(0.5)$ \\
\hline $\begin{array}{l}\% \text { Energy from } \\
\text { monounsaturated fat }\end{array}$ & $11.7(2.5)$ & $11.5(2.6)$ & $11.9(2.5)$ & $11.9(2.5)$ & $11.7(2.7)$ & $12.0(2.5)$ & $-0.2(2.8)$ & $0.2(3.2)$ & $0.1(2.6)$ \\
\hline $\begin{array}{l}\% \text { Energy from } \\
\text { polyunsaturated fat }\end{array}$ & $6.5(2.2)$ & $6.7(2.4)$ & $6.4(2.1)$ & $6.6(1.9)$ & $6.6(1.9)$ & $6.6(1.9)$ & $0.1(2.4)$ & $0.0(2.6)$ & $0.2(2.3)$ \\
\hline$\%$ Energy from total sugar & $17.2(5.7)$ & $18.7(5.5)$ & $16.5(5.6)^{b}$ & $17.7(5.7)$ & $18.8(5.4)$ & $17.2(5.8)^{\mathrm{a}}$ & $0.5(5.0)$ & $0.2(5.2)$ & $0.7(4.9)$ \\
\hline$\%$ Energy from alcohol & $3(0-8)$ & $1(0-5)$ & $5(0-9)^{c}$ & $2(0-7)$ & $0(0-6)$ & $2(0-7)^{a}$ & $0(-3-1)^{z}$ & $0(-1-2)$ & $-1(-4-0)^{\mathrm{c} \mathrm{z}}$ \\
\hline
\end{tabular}


the 4 days and $8 \%$ of women and $19 \%$ of men reporting more than $30 \mathrm{~g}$ of alcohol per day $(\mathrm{p}=0.022)$.

At 6 months, the mean daily reported energy intake was reduced by $187 \mathrm{kcal}(\mathrm{p}<0.001)$. Men reduced their energy intake more than women $(218 \pm 332$ vs 123 $\pm 270 \mathrm{kcal} /$ day, $\mathrm{p}=0.022)$. This was achieved by small reductions in all macronutrients, while maintaining fibre intake. The mean percentage energy from macronutrients was unchanged for women while men reported a small mean increase of $1.4 \pm 5.9 \% \quad(p<0.001)$ of energy from carbohydrates. Men reported reducing their median alcohol intake $(\mathrm{p}<0.001)$, with $40 \%$ reporting no alcohol during the 4 days and $15 \%$ reporting more than $30 \mathrm{~g} /$ day. There was no reported median change in alcohol intake for women. Despite no mean change to energy from saturated fat, more men met recommendations at 6 months $(35 \%$ men at baseline vs $49 \%$ at 6 months reporting less than $10 \%$ energy from saturated fat, $\mathrm{p}=0.007$ ). There was no change in the number of women meeting recommendations $(40 \%$ baseline vs $44 \%$ at 6 months, $\mathrm{p}=0.71$ ).

Valid physical activity data and dietary data were provided by $223(45 \%)$ participants. Table 3 shows the regression coefficients and CIs for changes in energy and macronutrients that show evidence of associations with specific metabolic variables. In men, a $1 \%$ reduction in energy from alcohol was associated with a $0.276 \mathrm{~mm} \mathrm{Hg}$ reduction in diastolic blood pressure (95\% CI 0.055 to 0.497 ). In women, a $1 \%$ reduction in energy from trans fat was associated with a decrease in cholesterol of $0.399 \mathrm{mmol} / \mathrm{L}$ (95\% CI 0.028 to 0.770 ). In men, a $1 \%$ increase in energy from carbohydrate was associated with a decrease in HbAlc of $0.003 \%(95 \%$ CI -0.006 to -0.001$)$. There were no associations between change in energy intake and the metabolic variables.

\section{DISCUSSION}

Main findings

The main findings from this exploratory analysis are that patients who were randomised to the intervention arms in the Early ACTID study and returned food diaries reported a good diet at baseline but still achieved small dietary changes. They reported a mean decrease in energy intake of around $200 \mathrm{kcal} /$ day during the first 6 months. This is a modest reduction in calorie intake, but if sustained will have an impact on weight and glycaemic control. It has been argued that small changes in the long term are more effective for weight management than large changes in the short term. ${ }^{27}$ Men reported a reduced alcohol intake that produced a greater reduction in energy and reported a small increase in the percentage energy from carbohydrate. Women reported modest reductions to all macronutrients but made no changes to alcohol, their energy reduction was less and the macronutrient ratio of their diets did not change. Both sexes maintained fibre intake. Although changes in percentage intake of macronutrients were associated with metabolic outcomes, these effect sizes were too small to be of clinical significance.

\section{Comparison with other studies}

The Early ACTID dietary intervention was a pragmatic, 'real world' intervention, in which participants discussed dietary advice with dietitians and nurses to decide on their own dietary changes. The approach contrasts with dietary studies where participants are asked to make specific, prescribed changes to the macronutrient composition, by lowering carbohydrate and increasing protein, ${ }^{28-30}$ or to lower the glycaemic index..$^{31}{ }^{32}$ The LOADD trial ${ }^{3}$ based a successful dietary intervention in patients with poor glycaemic control on very similar recommendations to those used in the Early ACTID intervention, but total energy intake and macronutrient ratios for each participant were calculated and diets were prescribed according to these calculations taking into account personal preference, budget and sociocultural factors. The Early ACTID intervention did not compare a prescriptive with a non-prescriptive approach, so it cannot be used to demonstrate that this is superior, but reductions in weight, waist circumference and HbAlc were achieved that are comparable to those achieved during these interventions. Withdrawal rates for prescriptive dietary interventions range from $10 \%$ to $30 \%$ and these higher withdrawal rates may suggest that in routine clinical care a more flexible approach can be advantageous in promoting retention. Of those participants in Early ACTID who either did not attend all appointments or withdrew completely, only one person stated that they did not see the benefit of the trial. The majority could not schedule all nine dietitian and nurse visits because of other commitments, five cited other health issues, three moved too far away, one said they 'did not want to diet,' one wanted to take orlistat from baseline and three gave no reasons. What is common to intervention trials in diabetes is that patients receive individual support and attend multiple appointments with a dietitian or a health practitioner who is an expert in promoting dietary change. It is important to emphasise that this model is not routinely replicated in primary care for patients with type $2 \mathrm{DM}$.

Exploratory analysis of the associations between specific dietary changes and metabolic outcomes found small effect sizes that are not clinically important, but they are consistent with existing nutritional data on the benefits of a reduction in trans fats on lipids and waist circumference, ${ }^{33}$ an increase in fibre on LDL cholesterol $^{34}$ and a reduction in alcohol and blood pressure. ${ }^{35}$ It is of interest that this analysis found that there was no benefit in carbohydrate reduction in men with good glycaemic control who are already consuming a low-to-moderate carbohydrate diet. It is not possible to determine whether there is an optimum macronutrient distribution for T2 DM from this analysis, particularly in those with poor glycaemic control, but there is no unequivocal evidence that low-carbohydrate diets 
Table 3 Associations between macronutrients and metabolic outcomes in men $(n=148)$ and women $(n=75)$ who provided physical activity data

\begin{tabular}{|c|c|c|c|c|}
\hline Macronutrient & & Metabolic outcomes & $\begin{array}{l}\text { Regression coefficient, } \\
\text { B }(95 \% \mathrm{Cl})\end{array}$ & p value \\
\hline Change to \% energy from total carbohydrates & Men & $\mathrm{HbA} 1 \mathrm{c} \%(\mathrm{mmol} / \mathrm{L})$ & $\begin{array}{l}-0.003(-0.006 \text { to }-0.001) \\
(-0.005(-0.009 \text { to }-0.001))\end{array}$ & 0.009 \\
\hline \multirow[t]{2}{*}{ Change to fibre (NSP) intake $(\mathrm{g})$} & All & Total cholesterol & $-0.023(-0.044$ to -0.002$)$ & 0.033 \\
\hline & Men & Total cholesterol & $-0.025(-0.047$ to -0.003$)$ & 0.023 \\
\hline \multirow[t]{2}{*}{ Change to \% energy from total fat } & All & LDL cholesterol & 0.018 (0.003 to 0.032$)$ & 0.016 \\
\hline & Men & LDL cholesterol & 0.024 (0.006 to 0.042$)$ & 0.011 \\
\hline \multirow[t]{4}{*}{ Change to \% energy from trans fat } & All & Waist circumference & $0.014(0.003$ to 0.024$)$ & 0.011 \\
\hline & Women & Waist circumference & 0.029 (0.006 to 0.052$)$ & 0.015 \\
\hline & & Total cholesterol & $0.399(0.028$ to 0.770$)$ & 0.036 \\
\hline & & LDL cholesterol & $0.365(0.042$ to 0.688$)$ & 0.028 \\
\hline Change to \% energy from monounsaturated fats & All & LDL cholesterol & 0.036 (0.006 to 0.065$)$ & 0.018 \\
\hline \multirow[t]{2}{*}{ Change to \% energy from alcohol } & All & Diastolic blood pressure & $0.217(0.020$ to 0.414$)$ & 0.031 \\
\hline & Men & Diastolic blood pressure & $0.276(0.055$ to 0.497$)$ & 0.015 \\
\hline $\begin{array}{l}\text { models are adjusted for change in energy intake, } \\
\text { etformin, sulfonylureas, glitazones), lipid lowering } n \\
\text { derate-to-vigorous physical activity. } \\
\text { each macronutrient listed, a } 1 \% \text { ( } 1 \mathrm{~g} \text { for fibre) incr }\end{array}$ & come at & $\begin{array}{l}\text { eline, age, BMI, time since } \\
\text { tihypertensives, dietary su }\end{array}$ & $\begin{array}{l}\text { ynosis, relevant hypoglycaemic } \\
\text { ments, mean daily minutes of } \\
\text { e listed. }\end{array}$ & \\
\hline
\end{tabular}

produce better blood glucose control or weight loss than higher carbohydrate diets. ${ }^{36}$ A meta-analysis of lowcarbohydrate diets versus low-fat diets conducted in $2012^{37}$ concluded that there was evidence of a small but beneficial effect on lipid profiles of a low (defined as $<45 \%$ energy from carbohydrate) or very low carbohydrate $(<60 \mathrm{~g}$ carbohydrate) diet but no difference in improvements to weight or glycaemic control. Larsen et $a l^{29}$ correlated dietary change with metabolic outcomes and found associations with energy reduction and HbA1c and waist circumference.

\section{Strengths and weaknesses}

To the best of our knowledge, this is the first study to describe the dietary intake of people soon after diagnosis with type $2 \mathrm{DM}$ living in the UK, the dietary changes made during an intervention based on patient-centred, non-prescriptive dietary advice and that examines associations between dietary change and metabolic variables. The demographics of the Early ACTID participants included in this analysis suggest that these findings are only representative of the white population; however, the sample is socioeconomically diverse with $40 \%$ of the participants living in areas of high economic deprivation. Ethical approval was granted to make no changes to hypoglycaemic, lipid lowering or blood pressure medications during the first 6 months, unless absolutely necessary, and this was controlled by a strict protocol. Owing to the small numbers, those participants who made medication changes were included in the analysis without correction.

The study has important weaknesses. Only 53\% of the participants returned the baseline and 6 month food diaries at the end of the trial, and these people had a lower BMI and waist circumference at baseline and achieved greater metabolic improvements. The participants who did not return the diaries reported mislaying them, which may indicate less motivation and less engagement with the trial. Participants who did return the diaries could have been more motivated to make dietary changes than a typical patient population, and given that their diets were good at baseline, may already have made dietary changes prior to entry into the Early ACTID study. The relative lack of dietary data limits our ability to generalise these findings to broader patient groups. Furthermore, this was an exploratory analysis using an existing dataset and as such an estimation of sample size was not conducted in advance. However, post hoc sample calculations indicate that the study was underpowered to detect small associations between dietary changes and metabolic outcomes, having $15 \%$ power for women and $52 \%$ for men at an $\alpha$ of 0.05 .

The use of any self-reported measure of diet, including 4-day food diaries, is a recognised limitation in dietary studies. Under-reporting of food intake and selective under-reporting or under-eating of foods perceived to be 'bad' are commonly documented, especially in people who are obese. ${ }^{38} 39$ Measurement of alcohol can be problematic due to the episodic nature of consumption, although including at least one weekend day can improve estimates by including alcohol consumption of 'weekend-only' drinkers. ${ }^{40}$ Methods exist to estimate under-reporting, using the calculated basal metabolic rate and estimates of physical activity, ${ }^{41} 42$ but these methods assume that an individual's weight is stable and are consequently inappropriate for use during a weight loss trial. It should be noted that other dietary interventions in patients with type $2 \mathrm{DM}$ have reported similar energy intakes ${ }^{28} 31$ and an energy reduction of around 
$200 \mathrm{kcal} /$ day is plausible assuming a dynamic model of energy balance ${ }^{43}$ and given the modest weight reduction observed. It is also important to note that this is a secondary analysis, so cause and effect cannot be assumed. It was not possible to perform a formal mediation analysis since participants from the control arm were not asked to complete a food diary at 6 months.

\section{CONCLUSION}

The Early ACTID trial indicates that a flexible, nonprescriptive approach to dietary advice based on standard healthy eating guidelines in type $2 \mathrm{DM}$ given soon after diagnosis may be effective in promoting small dietary change, even in patients with good glycaemic control. This supports current clinical practice and guidelines. The current analysis suggests that changes in percentage intake of macronutrients do not have any clinically significant effect on metabolic outcomes. However, this needs confirmation in a larger cohort, with less good glycaemic control. Further research is needed on whether dietary changes made using a nonprescriptive approach are sustainable and beneficial in the longer term in a more typical patient population.

\author{
Author affiliations \\ ${ }^{1}$ Centre for Exercise Nutrition and Health Sciences, School for Policy Studies, \\ University of Bristol, Bristol, UK \\ ${ }^{2}$ University of Birmingham, School of Sport, Exercise \& Rehabilitation \\ Sciences, Birmingham, UK \\ ${ }^{3}$ School of Clinical Sciences, University of Bristol, Learning and Research, \\ Southmead Hospital, Bristol, UK
}

Acknowledgements The authors acknowledge the participants in the Early ACtivity in Diabetes (Early ACTID) trial, members of the Early ACTID team and steering committee, Dr Pauline Emmett for advice on dietary analysis, $\mathrm{Dr}$ Rosemary Greenwood for advice on statistical analysis and Professor Debbie Sharp for assistance in manuscript preparation.

Contributors This work forms part of the PhD thesis of CYE, which is supervised by RCA, JLT and RJ. RCA led the Early ACtivity in Diabetes (Early ACTID) study and advised on the clinical application of this work. CYE participated in data collection, data entry and was responsible for data analysis with guidance from JLT and RJ. ARC was responsible for the design of the ACTID physical activity intervention and for processing and analysis of the physical activity data. The first draft of the manuscript was prepared by CYE with critical input and revisions by all other authors. All authors approved the final manuscript.

Funding The Early ACtivity in Diabetes (Early ACTID) trial was supported by Diabetes UK, the UK Department of Health and Western Comprehensive Local Research Network. Pilot dietary analysis was supported by the Above and Beyond Foundation. CYE is funded by NIHR Clinical Doctoral Research Fellowship 10017.

Competing interests None.

Ethics approval Bath Research Ethics Committee (05/Q2001/5).

Provenance and peer review Not commissioned; externally peer reviewed.

Data sharing statement No additional data are available.

Open Access This is an Open Access article distributed in accordance with the Creative Commons Attribution Non Commercial (CC BY-NC 3.0) license, which permits others to distribute, remix, adapt, build upon this work noncommercially, and license their derivative works on different terms, provided the original work is properly cited and the use is non-commercial. See: http:// creativecommons.org/licenses/by-nc/3.0/

\section{REFERENCES}

1. Inzucchi S, Bergenstal R, Buse J, et al. Management of hyperglycaemia in type 2 diabetes: a patient-centered approach. Position statement of the American Diabetes Association (ADA) and the European Association for the Study of Diabetes (EASD). Diabetologia 2012;55:1577-96.

2. Wing RR, Lang W, Wadden TA, et al. Benefits of modest weight loss in improving cardiovascular risk factors in overweight and obese individuals with type 2 diabetes. Diabetes Care 2011;34:1481-6.

3. Coppell KJ, Kataoka M, Williams SM, et al. Nutritional intervention in patients with type 2 diabetes who are hyperglycaemic despite optimised drug treatment-Lifestyle Over and Above Drugs in Diabetes (LOADD) study: randomised controlled trial. BMJ 2010;341: c3337.

4. Andrews RC, Cooper AR, Montgomery AA, et al. Diet or diet plus physical activity versus usual care in patients with newly diagnosed type 2 diabetes: the Early ACTID randomised controlled trial. Lancet 2011;378:129-39.

5. Aschner P, Katzeff HL, Guo H, et al. Efficacy and safety of monotherapy of sitagliptin compared with metformin in patients with type 2 diabetes. Diabetes Obes Metab 2010;12:252-61.

6. The Look AHEAD Research Group. Cardiovascular effects of intensive lifestyle intervention in type 2 diabetes. $N$ Engl J Med 2013;369:145-54.

7. Ajala O, English P, Pinkney J. Systematic review and meta-analysis of different dietary approaches to the management of type 2 diabetes. Am J Clin Nutr 2013:97:505-16.

8. Franz MJ, Powers MA, Leontos $C$, et al. The evidence for medical nutrition therapy for type 1 and type 2 diabetes in adults. J Am Diet Assoc 2010;110:1852-89.

9. Dyson PA, Kelly T, Deakin T, et al. Diabetes UK evidence-based nutrition guidelines for the prevention and management of diabetes. Diabet Med 2011;28:1282-8.

10. Northstone K, Emmett PM. Dietary patterns of men in ALSPAC: associations with socio-demographic and lifestyle characteristics, nutrient intake and comparison with women's dietary patterns. Eur J Clin Nutr 2010;64:978-86.

11. Hoare J, Henderson L, Bates CJ. National Diet and Nutrition Survey: adults aged 19 to 64 years. Vol 5. Summary Report. 2004.

12. England CY, Andrews R, Jago R, et al. Changes in reported food intake in adults with type 2 diabetes in response to a nonprescriptive dietary intervention. J Hum Nutr Diet 2013. Published Online First: Aug 2013. doi: 10.1111/jhn.12154

13. Cooper A, Sebire S, Montgomery A, et al. Sedentary time, breaks in sedentary time and metabolic variables in people with newly diagnosed type 2 diabetes. Diabetologia 2012:55:589-99.

14. Malpass A, Andrews R, Turner KM. Patients with type 2 diabetes experiences of making multiple lifestyle changes: a qualitative study. Patient Educ Couns 2009;74:258-63.

15. Connor H, Annan F, Bunn E, et al. The implementation of nutritional advice for people with diabetes. Diabetic Med 2003;20:786-807.

16. Miller WR. Motivational interviewing: research, practice, and puzzles. Addict Behav 1996;21:835-42.

17. Social Disadvantage Research Centre. The English indices of deprivation 2004. In: Research Department of Social Policy and Social Research Communities and Local Government, Oxford, 2004:14-42.

18. Price GM, Paul AA, Key FB, et al. Measurement of diet in a large national survey: comparison of computerized and manual coding of records in household measures. J Hum Nutr Diet 1995;8:417-28.

19. Cowin I, Emmett P, the ALSPAC study team. Diet in a group of 18-month-old children in South West England, and comparison with the results of a national survey. J Hum Nutr Diet 2000;13:87-100.

20. Holland B, Welch AA, Unwin ID, et al. McCance and Widdowson's the composition of foods. 5th edn. Cambridge: Royal Society of Chemistry, 1991.

21. Dennis B, Stamler J, Buzzard M, et al. INTERMAP: the dietary data -process and quality control. J Hum Hypertens 2003;17:609-22.

22. Wreiden WL, Barton KL. Calculation and collation of typical food portion sizes for adults aged 19-64 and older people aged 65 and over. Final Technical Report to the Food Standards Agency. 2006. http://www.foodbase.org.uk/results.php?f_report_id=82

23. Hu FB, Stampfer MJ, Rimm E, et al. Dietary fat and coronary heart disease: a comparison of approaches for adjusting for total energy 
intake and modeling repeated dietary measurements. Am J Epidemiol 1999;149:531-40.

24. Sterne JAC, Cox DR, Smith GD. Sifting the evidence-what's wrong with significance tests? Another comment on the role of statistical methods. BMJ 2001;322:226-31.

25. Perneger TV. What's wrong with Bonferroni adjustments. BMJ 1998;316:1236-8.

26. Rothman KJ. No adjustments are needed for multiple comparisons. Epidemiology 1990;1:43-6.

27. Hills AP, Byrne NM, Lindstrom R, et al. 'Small changes' to diet and physical activity behaviors for weight management. Obes Facts 2013;6:228-38.

28. Krebs J, Elley C, Parry-Strong A, et al. The Diabetes Excess Weight Loss (DEWL) Trial: a randomised controlled trial of high-protein versus high-carbohydrate diets over 2 years in type 2 diabetes. Diabetologia 2012;55:905-14.

29. Larsen RN, Mann NJ, Maclean E, et al. The effect of high-protein, low-carbohydrate diets in the treatment of type 2 diabetes: a 12 month randomised controlled trial. Diabetologia 2011:54:731-40.

30. Guldbrand H, Dizdar B, Bunjaku B, et al. In type 2 diabetes, randomisation to advice to follow a low-carbohydrate diet transiently improves glycaemic control compared with advice to follow a low-fat diet producing a similar weight loss. Diabetologia 2012;55:2118-27. doi:10.1007/s00125-012-2567-4

31. Jenkins DJ, Kendall CW, McKeown-Eyssen G, et al. Effect of a low-glycemic index or a high-cereal fiber diet on type 2 diabetes: a randomized trial. JAMA 2008;300:2742-53.

32. Wolever TM, Gibbs AL, Mehling C, et al. The Canadian Trial of Carbohydrates in Diabetes (CCD), a 1-y controlled trial of low-glycemic-index dietary carbohydrate in type 2 diabetes: no effect on glycated hemoglobin but reduction in C-reactive protein. $\mathrm{Am} \mathrm{J}$ Clin Nutr 2008;87:114-25.

33. Bhardwaj S, Passi SJ, Misra A. Overview of trans fatty acids: biochemistry and health effects. Diabetes Metab Syndr 2011;5:161-4.
34. Babio N, Balanza R, Basulto J, et al. Dietary fibre: influence on body weight, glycemic control and plasma cholesterol profile. Nutr Hosp 2010;25:327-40.

35. McFadden CB, Brensinger CM, Berlin JA, et al. Systematic review of the effect of daily alcohol intake on blood pressure. Am $J$ Hypertens 2005;18:276-86.

36. Castaneda-Gonzalez LM, Bacardi Gascon M, Jimenez Cruz A Effects of low carbohydrate diets on weight and glycemic control among type 2 diabetes individuals: a systemic review of RCT greater than 12 weeks. Nutr Hosp 2011;26:1270-6.

37. Hu T, Mills KT, Yao L, et al. Effects of low-carbohydrate diets versus low-fat diets on metabolic risk factors: a meta-analysis of randomized controlled clinical trials. Am J Epidemiol 2012;176(Supp 7):S44-54.

38. Karelis AD, Lavoie M-E, Fontaine J, et al. Anthropometric, metabolic dietary and psychosocial profiles of underreporters of energy intake: a doubly labeled water study among overweight/obese postmenopausal women-a Montreal Ottawa New Emerging Team study. Eur J Clin Nutr 2010;64:68-74.

39. Goris $\mathrm{AH}$, Westerterp-Plantenga MS, Westerterp KR. Undereating and underrecording of habitual food intake in obese men: selective underreporting of fat intake. Am J Clin Nutr 2000;71:130-4.

40. Room R, Mäkelä $P$, Benegal V, et al. Times to drink: cross-cultural variations in drinking in the rhythm of the week. Int $J$ Public Health 2012;57:107-17.

41. Black AE. Critical evaluation of energy intake using the Goldberg cut-off for energy intake: basal metabolic rate. A practical guide to its calculation, use and limitations. Int J Obes Relat Metab Disord 2000;24:1119-30

42. Rennie KL, Coward A, Jebb SA. Estimating under-reporting of energy intake in dietary surveys using an individualised method. $\mathrm{Br} J$ Nutr 2007;97:1169-76.

43. Hall KD, Sacks G, Chandramohan D, et al. Quantification of the effect of energy imbalance on bodyweight. The Lancet 2011;378:826-37. 